\title{
Blood homocysteine and fasting insulin levels are reduced and erythrocytesedimentation rates increased with a glycophospholipid- vitamin formulation: a retrospective study in older subjects
}

\author{
Rita R. Ellithorpe, ${ }^{1}$ Robert Settineri, ${ }^{2}$ Talon Ellithorpe, ${ }^{1}$ and Garth L. Nicolson, ${ }^{3 *}$ \\ ${ }^{1}$ Tustin Longevity Center, Tustin, California 92780, USA; ${ }^{2}$ Sierra Research, Irvine, California \\ 92606, USA; ${ }^{3}$ Department of Molecular Pathology, The Institute for Molecular Medicine, \\ Huntington Beach, California 92647, USA
}

Corresponding author: Prof. Garth Nicolson, Office of the President, The Institute for Molecular Medicine, P.O. Box 9355, S. Laguna Beach, CA 92652USA

Submission date: March 9, 2015; Acceptance date: April 10, 2015: Publication date: April 12, 2015

\begin{abstract}
Background: Elevations in Homocyteine (Hcys) levels in the blood have been correlated with increased risk for coronary heart disease and stroke, loss of cognition and memory, and other chronic medical conditions.
\end{abstract}

Objective: A retrospective study was initiated to determine if Hcys levels and other blood markers were altered in subjects taking an oral functional food supplement containing a mixture of phosphoglycolipids (NT Factor®) and vitamins.

Methods: Thirty-five patients ( 28 females, 7 males, Av. Age $=60.7 \pm 9.6$ years) who had used the functional food Advanced Physician's Formula ${ }^{\mathrm{TM}}$ with NTFactor® in tablet form each day were enrolled in a retrospective study on blood chemistry. This retrospective study followed a prospective study on the use of the same supplement to reduce fatigue in patients with chronic fatigue. Participants were patients with chronic fatigue syndrome (myalgic encephalomyelitis) or other fatiguing illnesses. Subjects had blood drawn over a 6-month period, and routine blood testing was performed. In this laboratory study, the results were analyzed for differences and statistical analyses were performed.

Results: All participants responded in the study and demonstrated an average reduction of $31.8 \%$ in Hcys levels (from 10.85 \pm 0.42 to $7.40 \pm 0.42 \mu \mathrm{mol} / \mathrm{L}$; t-test, $\mathrm{p}<0.001$; Wilcoxon, $\mathrm{p}<0.001$ ). Women responded better than men: women (from $11.06 \pm 0.50$ to $8.67 \pm 0.82 \mu \mathrm{mol} / \mathrm{L}, 34.4 \%$ reduction, t-test, $\mathrm{p}<0.001$; Wilcoxon, $\mathrm{p}<0.001$ ) versus men (from $10.80 \pm 0.51$ to $7.01 \pm 0.47$ $\mu \mathrm{mol} / \mathrm{L}, 21.6 \%$ reduction, $\mathrm{t}$-test, $\mathrm{p}<0.0862$ ). Differences were also found in fasting insulin levels (from $12.80 \pm 3.11$ to $5.30 \pm 1.77 \mu \mathrm{IU} / \mathrm{mL}, 58.6 \%$ reduction, t-test, $\mathrm{p}<0.005$ ) and erythrocyte sedimentation rate (ESR). ESR increased from $10.5 \pm 2.21$ to $20.19 \pm 3.20 \mathrm{~mm} / \mathrm{hr}(92.2 \%$ increase, t-test, $\mathrm{p}<0.0314$; Wilcoxon, $\mathrm{p}<0.0154)$. Other tests were not significantly different after 6 months 
of supplement, there were no side effects from the test supplement, and none of the participants had any cardiovascular events during the study.

Conclusions: The test formulation was effective in reducing Hcys and fasting insulin blood levels, and increasing ESR rates in older subjects without adverse effects.

Keywords: Lipid Replacement Therapy, NT Factor ${ }^{\circledR}$, fatigue, homocysteine, blood insulin, erythrocyte sedimentation rate, vitamin B complex

\section{BACKGROUND:}

Elevations in Homocyteine (Hcys) levels in the blood have been correlated with increased risk for coronary heart disease (CHD) and stroke, loss of cognition and memory, and other chronic medical conditions [1-4]. For example, Hcys can be high in chronic renal failure, hypothroidism, pernicious anemia, systemic lupus, certain methionine genetic alternations and deficiencies in folic acid, vitamin B6 and B12 or in heavy smokers or excess drug use [5]. But its role as an independent risk factor for arteriosclerotic and thromboembolic diseases', including myocardial infarction, cerebral infarction and deep-vein thrombosis, is what makes it important as a blood marker [6-8].

\section{INTRODUCTION:}

Recent clinical trials have demonstrated the effectiveness of Lipid Replacement Therapy (LRT) and antioxidants in the treatment of certain clinical disorders and conditions, such as chronic fatigue and fatiguing illnesses [9, 10]. This dietary approach to replace damaged cellular lipids with undamaged (unoxidized) lipids ensures proper function of cellular structures, such as cellular and organelle membranes [10-12]. LTR has been proven to be effective method in preventing Reactive Oxygen Species (ROS)-associated changes in function and for use in the treatment of various chronic conditions [9-12]. Chronic or intractable fatigue which is not reversed by sleep occurs naturally during aging and in many degenerative diseases [13, 14]. Chronic fatigue is the most common complaint of patients seeking general medical care in North America [13, 14], and it is associated with many normal activities, such as sports and physical training, as well as certain occupations [15-17].

In the design of clinical trials to reverse chronic fatigue various LRT products have been used [10]. For example, one of these clinical trials used a formulation that included NT Factor® and a combination of vitamins and other ingredients [20]. After this trial was completed, participants continued receiving the test supplement for at least 6 months. This allowed us to continue following the patients during routine clinic visits where basic health assessments were undertaken as well as laboratory tests, such as routine blood chemistry. The results of several patients suggested that their levels of Hcys were declining with continued use of the test supplement. As a result, we decided to retrospectively examine the blood levels of Hcys and other blood components in subjects that continued on LRT.

\section{SUBJECTS AND METHODS:}

Subjects. Thirty-five patients ( 28 females, 7 males, Av. Age $=60.7 \pm 9.6$ years) from a previously approved clinical trial [18] that had used the functional food Advanced Physician's Formula ${ }^{\mathrm{TM}}$ 
(Table 1) in tablet form each day were enrolled in a follow-on retrospective study on blood chemistry. Participants were patients with chronic fatigue or other fatiguing illnesses [18]. Participants had blood drawn at various times over a 6-month period, and routine blood testing was performed. In this retrospective laboratory study, the results were analyzed for differences and statistical analyses were performed (see below). Subjects were asked if they used any prescription medications to see if this would exclude them from the study, as determined previously [19], and their general health was assessed by a physician [13, 14].

Table 1. Test Supplement (Advanced Physicians Formula ${ }^{\mathrm{TM}}$ with NT Factor ${ }^{\circledR}$ and vitamins)

\begin{tabular}{|c|c|c|}
\hline Component & $\begin{array}{l}\text { Amount Per } \\
\text { Serving }\end{array}$ & $\begin{array}{l}\% \text { Daily } \\
\text { Value* }\end{array}$ \\
\hline NT Factor ${ }^{\#}{ }^{\text {(phospholipids) }}$ & $4,000 \mathrm{mg}$ & $* *$ \\
\hline Vitamin E (as d- $\alpha$-tocopheryl succinate, mixed tocopherols) & $50 \mathrm{IU}$ & 167 \\
\hline Thiamin (Vitamin B-1) (as thiamine Hcl) & $3.75 \mathrm{mg}$ & 250 \\
\hline Riboflavin (Vitamin B-2) & $4.25 \mathrm{mg}$ & 250 \\
\hline Niacin (Vitamin B-3) (as niacinamide, niacin) & $100 \mathrm{mg}$ & 500 \\
\hline Vitamin B-6 (as pyridoxine $\mathrm{HCl}$ ) & $10 \mathrm{mg}$ & 500 \\
\hline Folate (as folic acid) & $800 \mathrm{mcg}$ & 200 \\
\hline Vitamin B-12 (as methylcobalamin, cyanocobalamin) & $1,000 \mathrm{mcg}$ & 16,667 \\
\hline Biotin & $750 \mathrm{mcg}$ & 250 \\
\hline Pantothenic acid (as d-calcium patothenate) & $25 \mathrm{mg}$ & 250 \\
\hline $\begin{array}{l}\text { Calcium (as dicalcium phosphate, carbonate, pyruvate, } \\
\text { Borogluconate, d-calcium pantothenate) }\end{array}$ & $400 \mathrm{mg}$ & 40 \\
\hline Phosphorus (as calcium phosphate) & $125 \mathrm{mg}$ & 13 \\
\hline Magnesium (as magnesium oxide) & $125 \mathrm{mg}$ & 31 \\
\hline Methylsulfonylmethane (OptiMSM ${ }^{\mathrm{TM}}$ ) & $364 \mathrm{mg}$ & $* *$ \\
\hline Alpha-keto-glutaric acid & $300 \mathrm{mg}$ & $* *$ \\
\hline 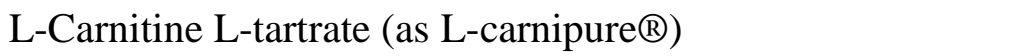 & $225 \mathrm{mg}$ & $* *$ \\
\hline L-Tyrosine & $150 \mathrm{mg}$ & $* *$ \\
\hline
\end{tabular}

*Daily values are based on a 2,000 calories per day diet

***Daily values not established

${ }^{\#}$ NT Factor ${ }^{\circledR}$ is a patented (U.S. Patent 8,877,239 B2) proprietary blend of food and food components: phosphoglycolipids (polyunsaturated phosphatidylcholine, glycolipids and other polyunsaturated phosphatidyl nutrients), Bifido and Lactobaccillus bacteria (freeze-dried and microencapsulated in viable form), growth media (bacterial growth factors and food, including rice bran extract, arginine, beet root fiber, black strap molasses, glycine, magnesium sulfate, para-amino benzoate, leek, pantethine, taurine, garlic, calcium borogluconate, potassium citrate, spriulina, bromelain, natural vitamin E, calcium ascorbate, $\alpha$-lipoic acid, oligosaccharides, vitamin B-6, niacinamide, riboflavin, vitamin B-12, folic acid, inositol, calcium pantotenate, chromium ficolinate). NT Factor ${ }^{\circledR}$ is a registered trademark of Nutritional Therapeutics Inc., Hauppauge, NY.

Methods. Subjects who had previously signed an informed consent document and completed a clinical trial on the use of a LRT supplement to reduce fatigue [18] were subsequently enrolled in this retrospective study on blood chemistry. Blood samples were taken at routine visits to the 
Tustin Longevity Center, Tustin, California under similar conditions of fasting and time of day, and were subjected to analysis. The results of this study were compared to visits during the previous clinical trial and subsequent visits after the trial was completed and just before starting the test supplement. Hcys was determined with an enzymatic cycling assay [21] using a kit from Diazyme Laboratories (San Diego, CA). Fasting insulin was determined by a solid-phase, twosite chemoluminescent method on an Immulite 1000 analyzer according to the manufacturer's instructions (Siemens Medical, Diagnostics Products Corporation division, Los Angeles, CA) [22]. Erythrocyte ESR determinations were performed with a modification of the Westergren method [23] using the Sediplast ESR system (Polymedco, Cortlandt Manor, NY). Routine blood chemistry was performed as described previously [18].

Statistics. Data was analyzed by ANOVA, with significance defined as $p<0.05$. Further data analysis was performed with Tukey test and Wilcoxon signed rank analysis, with significance defined as $\mathrm{p}<0.05$. The standardized alpha (Cronbach's alpha) was used to confirm reliability and internal consistency of the data [18].

\section{RESULTS:}

When analyzed after 6 months of test supplement, all participants in the study responded and revealed an average $31.8 \%$ in Hcys levels (from $10.85 \pm 0.42$ to $7.40 \pm 0.42 \mu \mathrm{mol} / \mathrm{L}$; $\mathrm{t}$-test, $\mathrm{p}<$ 0.001; Wilcoxon, $\mathrm{p}<0.001$ ) (Table 2). Women responded better than men: women (from $11.06 \pm 0.50$ to $8.67 \pm 0.82 \mu \mathrm{mol} / \mathrm{L}, 34.4 \%$ reduction, $\mathrm{t}$-test, $\mathrm{p}<0.001$; Wilcoxon, $\mathrm{p}<0.001$ ) versus men (from $10.80 \pm 0.51$ to $7.01 \pm 0.47 \mu \mathrm{mol} / \mathrm{L}, 21.6 \%$ reduction, $\mathrm{t}$-test, $\mathrm{p}<0.0862$ ). Differences were also found in fasting insulin levels (from $12.80 \pm 3.11$ to $5.30 \pm 1.77 \mu \mathrm{IU} / \mathrm{mL}, 58.6 \%$ reduction, t-test, $\mathrm{p}<0.005)$ and erythrocyte sedimentation rate $(\mathrm{ESR})$. ESR increased from $10.5 \pm 2.21$ to $20.19 \pm 3.20 \mathrm{~mm} / \mathrm{hr}(92.2 \%$ increase, $\mathrm{t}$-test, $\mathrm{p}<0.0314$; Wilcoxon, $\mathrm{p}<0.0154)$. There were also non-significant increases in iron and ferritin found at the end of the study.

Table 2. Blood chemistry values of participants before and 6-months after taking the test supplement

\begin{tabular}{|l|l|l|l|}
\hline Blood Meas. & Time $=\mathbf{0}$ Av. \pm SEM & $\begin{array}{l}\text { Time }=6 \text { mo Av. } \pm \text { SEM } \\
(\% \text { change) }\end{array}$ & Statist. Signif. \\
\hline Hycs & $10.85 \pm 0.42 \mu \mathrm{m} / \mathrm{L}$ & $7.40 \pm 0.41(-34.4 \%)$ & $\mathrm{p}<0.001$ \\
\hline Fast. Insulin & $12.80 \pm 3.1 \mu \mathrm{IU} / \mathrm{mL}$ & $5.30 \pm 1.77(-58.6 \%)$ & $\mathrm{p}<0.005$ \\
\hline ESR & $10.5 \pm 2.21 \mathrm{~mm} / \mathrm{hr}$ & $20.19 \pm 3.20(+92.2 \%)$ & $\mathrm{p}<0.003$ \\
\hline BUN & $17.63 \pm 4.4$ & $17.26 \pm 4.6$ & $\mathrm{NS}$ \\
\hline GGT & $33.01 \pm 5.9$ & $34.8 \pm 8.4$ & $\mathrm{NS}$ \\
\hline ALP & $61.2 \pm 3.5$ & $65.06 \pm 5.1$ & $\mathrm{NS}$ \\
\hline AST/ALT & $22.81 \pm 1.3$ & $24.03 \pm 2.8$ & $\mathrm{NS}$ \\
\hline CRP & $2.81 \pm 2.4$ & $2.02 \pm 2.8$ & $\mathrm{NS}$ \\
\hline HDL & $64.2 \pm 3.8$ & $62.3 \pm 2.8$ & $\mathrm{NS}$ \\
\hline LDL & $115.7 \pm 6.4$ & $119.1 \pm 7.5$ & $\mathrm{NS}$ \\
\hline Cholesterol & $199.5 \pm 8.4$ & $201.8 \pm 7.9$ & $\mathrm{NS}$ \\
\hline Chol/HDL & $3.18 \pm 0.3$ & $3.14 \pm 0.5$ & $\mathrm{NS}$ \\
\hline
\end{tabular}




\begin{tabular}{|l|l|l|l|}
\hline Blood Meas. & Time $=\mathbf{0}$ Av. \pm SEM & $\begin{array}{l}\text { Time }=6 \text { mo Av. } \pm \text { SEM } \\
(\% \text { change })\end{array}$ & Statist. Signif. \\
\hline Triglyceride & $98.1 \pm 9.1$ & $100.6 \pm 9.8$ & NS \\
\hline Sodium & $138.9 \pm 0.4$ & $138.6 \pm 0.3$ & NS \\
\hline Potassium & $4.14 \pm 0.05$ & $5.5 \pm 1.2$ & NS \\
\hline Iron & $80.5 \pm 9.5$ & $92.0 \pm 11.5$ & NS \\
\hline Ferritin & $39.2 \pm 14.9$ & $45.0 \pm 12.3$ & NS \\
\hline Creatine & $0.78 \pm 0.04$ & $0.83 \pm 0.03$ & NS \\
\hline
\end{tabular}

ALP, alkine phosphatase; BUN, blood urea nitrogen; CRP, c-reactive protein; ESR, erythrocyte sedimentation rate; GGT, gama-glutamyl transpeptidase; HDL, high-density lipoprotein; Hcys, homocysteine; LDL, low-density lipoprotein; AST/ALT, alanine aminotransferase

Other tests in the chemistry panel were not significantly different after 6 months of supplement (Table 2). Furthermore, there were no side effects from the test supplement, and none of the participants had any cardiovascular events during the study.

A few of the subjects in the study were analyzed at intermediate end-points (Figure 1). The changes in blood Hcys, fasting insulin and ESR were gradual during the course of the study, with not every participant demonstrating significant changes in all three of these parameters.

\section{DISCUSSION:}

Polyunsaturated glycophospholipids in the supplement in NT Factor ${ }^{\circledR}$ have been used successfully in animal and clinical lipid replacement studies [9-12, 18-20, 24]. In this formulation, encapsulated lipids are protected from oxidation in the gut and can be absorbed and transported into tissues without oxidative damage $[9,10]$. The NT Factor $®$ lipids are primarily membrane phospholipids and phosphoglycolipids that are normally found in all vertebrate cellular membranes [12].

Mitochondrial dysfunction and the accumulation of damaged mitochondrial components have been linked to a wide variety of chronic, metabolic and degenerative diseases, cancer and aging [9, 11, 25, 26]. Lipid Replacement has been successfully used in clinical studies to reduce fatigue, increase mitochondrial function and protect cellular and mitochondrial membranes from oxidative damage [reviewed in 9-11]. In multiple clinical studies, fatigue was reduced 35-43\% by oral administration of NT Factor ${ }^{\circledR}$ [9-11, 18-20]. Even in severely fatigued patients with chronic fatigue syndrome or fibromyalgia, NT Factor® reduced fatigue by $43.1 \%$ [9]. In a study conducted by Agadjadyan et al. [20], NT Factor® reduced fatigue $35.5 \%$ in aging adults, and significantly improved mitochondrial function to a similar level of that found in young, healthy adults. Therefore, LRT has the potential to decrease the effects of aging on mitochondrial function and improve mitochondrial function in chronic diseases.

Here we examined the effects of LRT on blood chemistry in a retrospective study using a supplement that contained NT Factor®, vitamins and other ingredients [18]. We found that blood Hcys and fasting insulin levels were significantly reduced, while ESR rates were significantly increased after 6 months on the test supplement. 


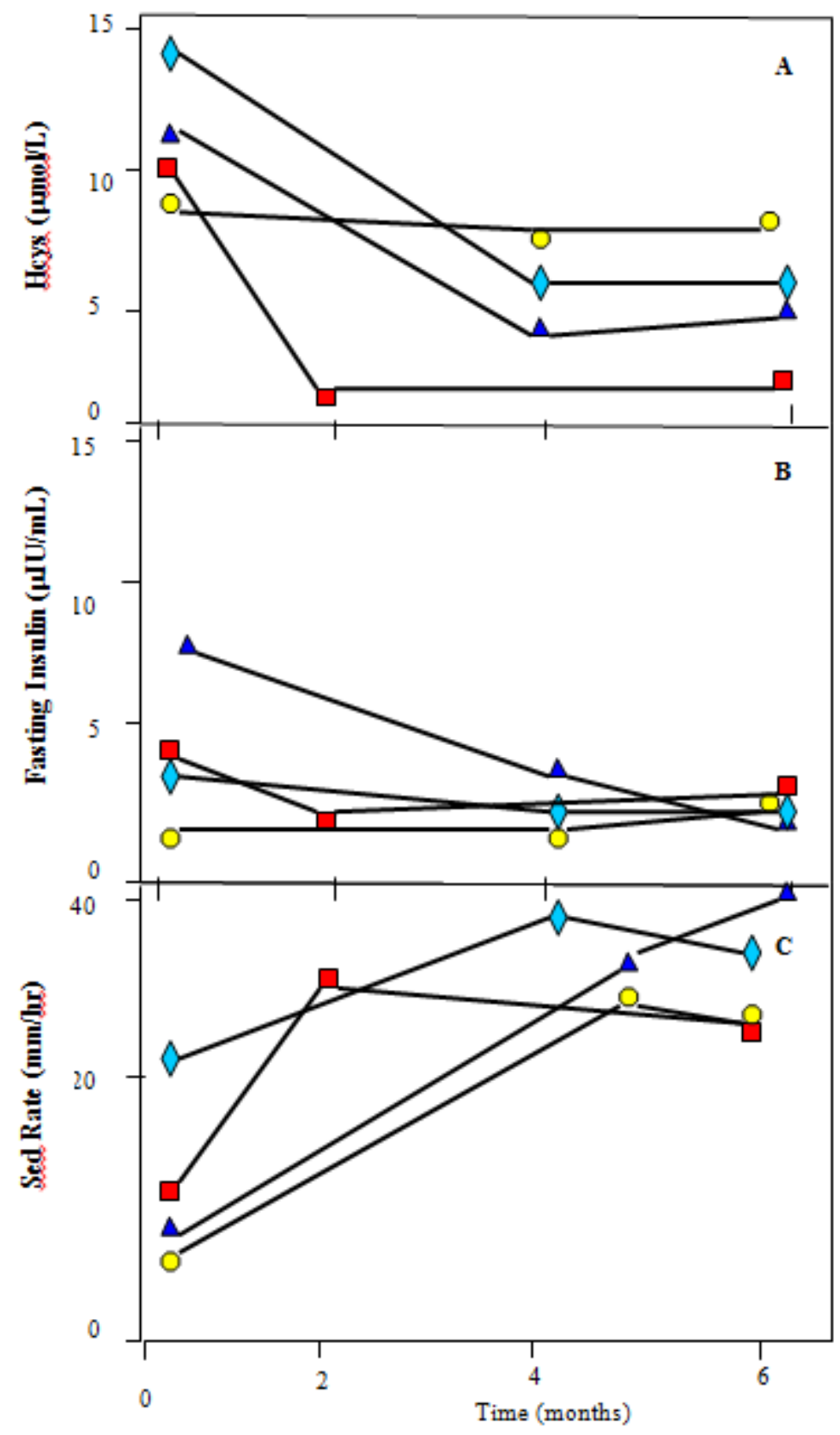

Figure 1. Time course of (A) Hcys, (B) fasting insulin and (C) ESR in four patients. The determinations are given as single test results over time.

Before our study, the participants had an average Hcys level of $10.85 \pm 0.42 \square$ mole/L, which is slightly above the level (10.8 $\square$ mole/L), which predicts the development of heart failure [27]. After 6 months on the test supplement, Hcys levels were significantly reduced to $7.40 \pm 0.42$ $\mu \mathrm{mol} / \mathrm{L}$, well below the level that can predict coronary problems in adults [27]. While these subjects were only followed for 6 months, there were no cases of coronary heart problems, strokes or other issues that could be related to elevated blood Hcys, even though the average age of this group was above 60 years. Although women in the study responded slightly better to the test supplement than men in terms of reduced blood Hcys levels, there may not have been 
enough men in the study to conclude, overall, that women respond to the test supplement better than men.

The test supplement used in the present study contained B-vitamins; the long-term use of high doses of B-vitamins, more than those used in the test supplement, have been demonstrated to have a modest effect on CHD and stroke [28]. The independent effect of B-vitamins in the test supplement could not be assessed in the current study, but it is doubtful that the results found here were simply due to the presence of B-vitamins. In a high-dose vitamin B study that examined Hcys levels over several years of use, the levels of Hcys were reduced an average of $2.2 \mu \mathrm{mol} / \mathrm{L}$ [29], which is less than that achieved with the test supplement used in the current study (an average reduction of $3.45 \mu \mathrm{mol} / \mathrm{L}$ ).

There were also changes in fasting insulin levels. There was a reduction in average fasting insulin level from $12.80 \pm 3.1$ to $5.30 \pm 1.77 \mu \mathrm{IU} / \mathrm{mL}$ (58.6\% reduction) after 6 months on the test formulation. Increased fasting insulin levels are positively associated with CHD and stroke, especially in women $[30,31]$. In a Canadian study, the average blood fasting insulin levels of 13 $\mu \mathrm{IU} / \mathrm{mL}$ or above correlated with an 8 -fold higher heart attack risk than an average level of 9.3 $\mu \mathrm{IU} / \mathrm{mL}$ [32]. The average fasting insulin levels for U.S. women is $8.4 \mu \mathrm{IU} / \mathrm{mL}$ and for men, 8.8 $\mu \mathrm{IU} / \mathrm{mL}$ [33]. Therefore, the test supplement reduced the level of fasting insulin to below average levels for women and men in the U.S. population.

In addition to reductions in Hcys and fasting insulin, subjects in the trial had an average increase in erythrocyte ESR rates, an independent risk marker for CHD [34] and especially CHD mortality in men [35]. This test is less impressive in predicting cardiovascular disease in women [36]. ESR rates are also modified in chronic inflammation, tissue injury, and collagen diseases and in many malignancies [37]. This test detects changes in the presence of acute phase reactants but it is not dependent on them to show changes [38]. Nonetheless, ESR rates were significantly increased during the trial from an average of $10.5 \pm 2.21$ to $20.19 \pm 3.20 \mathrm{~mm} / \mathrm{hr}$ (92.2\% increase). Interestingly, we did not find significant changes in C-reactive protein, a measurement that generally, but not always [38], parallels changes in ESR. The reason for this may be related to changes in erythrocyte membrane lipid composition which allow erythrocytes to be more flexible - thus increasing ESR values without affecting erythrocyte-erythrocyte aggregation. Evidence for this hypothesis comes from studies where polyunsaturated n-3 fatty acids were supplemented for 3 months in patients with cystic fibrosis. In parallel with changes in erythrocyte lipid composition, ESR rates were also found to be significantly increased [39]. Accordingly, the rheological properties of human red blood cells can change, depending on the amounts of saturated fats and cholesterol in the diet [40].

Finally, there were no cardiovascular events during the 6-month retrospective trial, and the test supplement was well tolerated. In fact, there were no incidents of adverse responses to the test supplement during this study. This demonstrates that the test supplement was a safe and effective method to improve blood markers that predict future CHD. The test supplement also reduced fatigue, as measured during the first prospective part of the trial. Fatigue was reduced by a mean of $36.8 \%$ during the first week of the original trial [18], and although fatigue was not measured at 6 months in this retrospective study, participants indicated that their lower fatigue levels were maintained while on the test supplement. 
Abbreviations Used: CHD, coronary heart disease, ESR, erythrocyte sedimentation rate; Hcys, homocysteine; LRT, Lipid Replacement Therapy; ROS, reactive oxygen species

Competing Interests: The authors have no financial interests or conflicts of interest.

Authors' Contributions: All authors contributed to this study.

Acknowledgements and Funding: The authors would like to thank Nutritional Therapeutics, Inc. and the Institute for Molecular Medicine for clinical trial financial support.

\section{REFERENCES:}

1. Nygard O, Vollset SE, Refsum H, Stensvold I, Tverdal A, Nordrehaug JE, Ueland M, Kvale G. Total plasma homocysteine and cardiovascular risk profile: the Hordaland Homocysteine Study. JAMA 1995; 274: 1526-1533.

2. Robinson K, Gupta A, Dennis V, Arheart K, Chaudhary D, Green R, Vigo P, Mayer EL, Selhub J, Kutner M, Jacobsen DW. Hyperhomocysteinemia confers an independent increased risk of atherosclerosis in end-stage renal disease and is closely linked to plasma folate and pyridoxine concentrations. Circulation 1996; 94: 2743-2748.

3. Feng L, Isaac V, Sim S, Ng TP, Krishnan KR, Chee MW. Associations between Elevated Homocysteine, Cognitive Impairment, and Reduced White Matter Volume in Healthy Old Adults. Am J Geriatr Psychiatry 2011; Dec 8. doi: 10.1097/JGP.0b013e31823e2fe3 [Epub ahead of print].

4. Sachdev PS, Lipnicki DM, Crawford J, Reppermund S, Kochan NA, Trollor JN, Draper B, Slavin MJ, Kang K, Lux O, Mather KA, Brodaty H. Risk profiles of subtypes of mild cognitive impairment: the sydney memory and ageing study. J Am Geriatr Soc 2012; 60(1): 24-33.

5. Taylor BV, Oudit GY, Evans M. Homocysteine, vitamins and coronary artery disease. Can Family Physician 2000; 46(11): 2236-2245.

6. Bostom AG, Selbub J. Homocysteine and arteriosclerosis: subclinical and clinical disease associations. Circulation 1999; 99: 2361-2363.

7. Clark R, Daly L, Robinson K, Naughten E, Cahalane S, Fowler B, Graham I. Hyperhomocysteinemia: an independent risk factor for vascular diseases. N Engl J Med 1991; 324: 1149-1155.

8. Bostom AG, Rosenbrg IH, Silbershatz H, Jacques PF, Rosenberg IH. Nonfastng plasma total homocysteine levels and stroke incidence in elderly persons: the Framingham Study. Ann Intern Med 1999; 131: 352-355.

9. Nicolson GL, Ellithrope R. Lipid replacement and antioxidant nutritional therapy for restoring mitochondrial function and reducing fatigue in chronic fatigue syndrome and other fatiguing illnesses. J Chronic Fatigue Syndr 2006; 13(1): 57-68.

10. Nicolson GL, Settineri R. Lipid Replacement Therapy: a functional food approach with new formulations for reducing cellular oxidative damage, cancer-associated fatigue and the adverse effects of cancer therapy. Funct Foods Health Dis 2011; 4: 135-160. 
11. Nicolson GL. Lipid Replacement Therapy: a nutraceutical approach for reducing cancerassociated fatigue and the adverse effects of cancer therapy while restoring mitochondrial function. Cancer Metastasis Rev 2010; 29(3): 543-552.

12. Nicolson GL. Lipid replacement as an adjunct to therapy for chronic fatigue, anti-aging and restoration of mitochondrial function. J Am Nutraceut Assoc 2003; 6(3): 22-28.

13. Kroenke K, Wood DR, Mangelsdorff AD, Meier NJ, Powell JB. Chronic fatigue in primary care. Prevalence, patient characteristics, and outcome. JAMA 1988; 260: 929-934.

14. Morrison JD. Fatigue as a presenting complaint in family practice. J Family Pract 1980; 10: 795-801.

15. Knicker AJ, Renshaw I, Oldham AR, Cairns SP. Interactive processes link the multiple symptoms of fatigue in sports competition. Sports Med 2011; 41: 307-328.

16. Purvis D, Gonsalves S, Deuster PA. Physiological and psychological fatigue in extreme conditions: overtraining and elite athletes. Phys Med Rehab 2010; 2: 442-450.

17. Sheaff AK, Bennett A, Hanson ED, Kim YS, Hsu J, Shim JK, Edwards ST, Hurley BF. Physiological determinants of the candidate physical ability test in firefighters. J Strength Cond Res 2010; 24: 3112-3122.

18. Nicoson GL, Ellithorpe RR, Ayson-Mitchell C, Jacques B, Settineri R. Lipid Replacement Therapy with a glycophospholipid-antioxidant-vitamin formulation significantly reduces fatigue within one week. J Am Nutraceutical Assoc 2010; 13(1): 11-15.

19. Ellithorpe RR, Settineri R, Nicolson GL. Pilot study: reduction of fatigue by use of a dietary supplement containing glycophospholipids. J Am Nutraceut Assoc 2003; 6(1): 23 28.

20. Agadjanyan M, Vasilevko V, Ghochikyan A, Berns P, Kesslak P, Settineri R, Nicolson GL. Nutritional supplement (NTFactor) restores mitochondrial function and reduces moderately severe fatigue in aged subjects. J Chronic Fatigue Syndr 2003; 11(3): 23-26.

21. Dao C, Xia D, Zhang L, Chen X, Flores P, Katta A, Yuan C. Development of a novel enzymatic cycling assay for total homocysteine. Clin Chem 2005; 51(10): 1987-1989.

22. Reeves WG. Insulin antibody determination: theoretical and practical considerations. Diabetologia 1983; 24: 399-403.

23. Westergren A. Diagnostic tests: the erythrocyte sedimentation rate, range and limitations of the technique. Triangle 1957; 3(1): 20-25.

24. Seidman M, Khan MJ, Tang WX, Quirk WS. Influence of lecithin on mitochondrial DNA and age-related hearing loss. Otolaryngol Head Neck Surg 2002; 127: 138-144.

25. Wallace DC. A mitochondrial paradigm of metabolic and degenerative diseases, aging and cancer: a dawn for evolutionary medicine. Annu Rev Genet 2005; 39: 359-407.

26. Wallace DC, Fan W, Procaccio V. Mitochondrial energetics and therapeutics. Annu Rev Pathol 2010; 5: 297-348.

27. Washio, T, Nomoto K, Watanabe I, Tani S, Nagao K, Hirayama A. Relationship between plasma homoccysteine levels and congestive heart failure in patients with acute myocardial infarction. Int Heart J 2011; 52: 224-228.

28. Schnyder G, Flammer Y, Roffi M, Pin R, Hess OM. Plasma homocysteine levels and late outcome after coronary angioplasty. J Am Coll Cardiol 2002; 40(10): 1769-1776. 
29. Saposnik G, Black S, Stroke Outcome Research Canada Working Group. Stroke outcome in the very elderly: hospital care, case fatality and disposition.. Cerebrovasc Dis 2009; 27(6): 537-543.

30. Folsom AR, Szklo M, Stevens J, Liao F, Smith R, et al. A prospective study of coronary heart disease in relation to fasting insulin, glucose and diabetes. The Atherosclerosis Risk in Communities (ARIC) Study. Diabetes Care 1997; 20(6): 935-942.

31. Lawlor DA, Fraser A, Ebrahim S, Smith GD. Independent associations of fasting insulin, glucose and glycated haemoglobin with stroke and coronary heart disease in older women. PLOS Med 2007; 4(8): 1396-1404.

32. Despres JP, Lamarche B, Mauriege P, Cantin B, Dagenais GR, Moorjani S, Lupien PJ. Hyperinsulinemia as an independent risk factor for ischemic heart disease. New Engl J Med 1996; 334(11): 952-957.

33. Harris MI, Cowie CC, Gu K, Francis ME, Fiegal K, Eberhardt MS. Higher fasting insulin but lower fasting C-peptide levels in African Americans in the US population. Diabetes Metab Res Rev 2002; 18(2): 149-155.

34. Yayan J. Erythrocyte sedimentation rate as a marker for coronary heart disease. Vasc Health Risk Manag 2012; 8: 219-223.

35. Erikssen G, Liestøl K, Bjørnholt JV, Stormorken H, Thaulow E, Erikssen J. Erythrocyte sedimentation rate: a possible marker of atherosclerosis and a strong preductor of coronary heart disease mortality. Eur Heart J 2000; 21(19): 1614-1620.

36. Rafnsson V, Bengtsson C. Erythrocyte sedimentation rate and cardiovascular disease. Results from a population study of women in Goteborg, Sweden. Atherosclerosis 1982; 42: 97-108.

37. Rapaport E. Erythrocyte sedimentation rate: is it a useful risk marker for coronary heart disease? Eur Heart J 2000; 21: 1567-1569.

38. Horsti J, Rontu R, Collings A. A comparison between the StaRRsed auto-compact erythrocyte sedimentation rate instrument and the Westergren method. J Clin Med Res 2010; 2(6): 261-265.

39. Keen C, Olin AC, Eriksson S, Ekman A, Lindblad A, Basu S, Beemann C, Strandvik B. Supplementation with fatty acids influences the airwa nitric oxide and inflammatory markers in patients with cystic fibrosis. J Pediatr Gastroenterol Nutr 2010; 50(5): 537-544.

40. Cicha I, Suzuki Y, Tateishi N, Maeda N. Effects of dietary triglycerides on rheological properties of human red blood cells. Clin Hemorheol Microcirc 2004; 30(3): 301-305. 